\title{
Current climate, isolation and history drive global patterns of tree phylogenetic endemism
}

\author{
Brody Sandel $^{1}$ (D) | Patrick Weigelt ${ }^{2}$ | Holger Kreft ${ }^{2}$ | Gunnar Keppel ${ }^{2,3,4}$ | \\ Masha T. van der Sande ${ }^{5,6,7}$ (D) | Sam Levin ${ }^{8,9}$ | Stephen Smith ${ }^{10}$ | Dylan Craven ${ }^{2,8,11}$ \\ Tiffany M. Knight ${ }^{8,9,11}$ \\ ${ }^{1}$ Department of Biology, Santa Clara University, Santa Clara, California \\ ${ }^{2}$ Biodiversity, Macroecology and Biogeography, University of Goettingen, Göttingen, Germany \\ ${ }^{3}$ Natural and Built Environments Research Centre, School of Natural and Built Environments, University of South Australia, Adelaide, South Australia, Australia \\ ${ }^{4}$ Future Industries Institute, University of South Australia, Mawson Lakes Campus, Adelaide, South Australia, Australia \\ ${ }^{5}$ Institute for Global Ecology, Florida Institute of Technology, Melbourne, Florida \\ ${ }^{6}$ Institute for Biodiversity \& Ecosystem Dynamics, University of Amsterdam, Amsterdam, The Netherlands \\ ${ }^{7}$ Forest Ecology and Forest Management Group, Wageningen University and Research, Wageningen, The Netherlands \\ ${ }^{8}$ German Centre for Integrative Biodiversity Research (iDiv) Halle-Jena-Leipzig, Leipzig, Germany \\ ${ }^{9}$ Institute of Biology, Martin Luther University Halle-Wittenberg, Halle (Saale), Germany \\ ${ }^{10}$ Department of Ecology and Evolutionary Biology, University of Michigan, Ann Arbor, Michigan \\ ${ }^{11}$ Department of Community Ecology, Helmholtz Centre for Environmental Research- UFZ, Halle (Salle), Germany
}

\section{Correspondence}

Brody Sandel, Department of Biology, Santa Clara University, 500 El Camino Real, Santa

Clara CA 95053, USA.

Email: bsandel@scu.edu

Funding information

Alexander von Humboldt-Stiftung;

Nederlandse Organisatie voor

Wetenschappelijk Onderzoek, Grant/Award

Number: 019.171LW.023

Editor: Ruth Kelly

\section{Abstract}

Aim: We mapped global patterns of tree phylogenetic endemism (PE) to identify hotspots and test hypotheses about possible drivers. Specifically, we tested hypotheses related to current climate, geographical characteristics and historical conditions and assessed their relative importance in shaping PE patterns.

Location: Global.

Time period: We used the present distribution of trees, and predictors covering conditions from the mid-Miocene to present.

Major taxa studied: All seed-bearing trees.

Methods: We compiled distributions for 58,542 tree species across 463 regions worldwide, matched these to a recent phylogeny of seed plants and calculated PE for each region. We used a suite of predictor variables describing current climate (e.g., mean annual temperature), geographical characteristics (e.g., isolation) and historical conditions (e.g., tree cover at the Last Glacial Maximum) in a spatial regression model to explain variation in $\mathrm{PE}$.

Results: Tree PE was highest on islands, and was higher closer to the equator. All three groups of predictor variables contributed substantially to the PE pattern. Isolation and topographic heterogeneity promoted high $\mathrm{PE}$, as did high current tree cover. Among mainland regions, temperature seasonality was strongly negatively related to $P E$, while mean annual temperature was positively related to $P E$ on islands. Some relationships differed among the major floristic regions. For example, tree cover at 
the Last Glacial Maximum was a positive predictor of PE in the Palaeotropics, while tree cover at the Miocene was a negative predictor of PE in the Neotropics.

Main conclusions: Globally, PE can be explained by a combination of geographical, historical and current factors. Some geographical variables appear to be key predictors of PE. However, the impact of historic and current climate variables differs considerably among the major floristic regions, reflecting their unique histories. Hence, the current distribution of trees is the result of globally relevant geographical drivers and regional climatic histories.

\section{KEYWORDS}

biogeography, climate stability, historical contingency, islands, isolation, phylogenetic endemism, trees

\section{INTRODUCTION}

The remarkable disparity in the distribution of terrestrial biodiversity has fascinated biologists for more than two centuries (Harrison \& Noss, 2017; Kier et al., 2009; von Humboldt \& Bonpland, 1807). Thirty-six recognized biodiversity hotspots, which cover $2.4 \%$ of the Earth's land surface, contain an estimated $50 \%$ of all endemic plant species and $42 \%$ of all endemic terrestrial vertebrate species (Hrdina \& Romportl, 2017; Myers, Mittermeier, Mittermeier, Fonseca, \& Kent, 2000). Endemism lies at the core of understanding the variation of biodiversity across space, revealing how speciation, extinction, dispersal and biophysical barriers influence species distributions (Lomolino et al., 2009). Traditionally, studies of endemism have focused on taxonomic measures of endemism, which only account for the number of endemic or range-restricted species in a particular area (Kier et al., 2009; Williams et al., 1996) and do not capture the rich history of how clades have diversified over evolutionary time (Mishler et al., 2014; Rosauer, Laffan, Crisp, Donnellan, \& Cook, 2009).

Phylogenetic endemism (PE) addresses this shortcoming by integrating evolutionary history (i.e., phylogenetic uniqueness) with the range sizes of clades, weighting each branch in a phylogenetic tree by the inverse of the descendent clade's total range size (Rosauer et al., 2009). Hence, geographical regions with high PE contain clades that are narrowly distributed and phylogenetically unique, and whose loss would lead to a large loss of evolutionary history. As such, PE can play a central role in conservation planning (Mishler et al., 2014). Further, spatial patterns of PE can unveil the roles played by speciation and extinction events in determining large-scale biodiversity patterns, such as the latitudinal diversity gradient (Schluter \& Pennell, 2017). For example, they can shed light on the long-standing question of whether the tropics are species rich because of high speciation rates (a cradle of diversity, producing clusters of closely related species and relatively low $\mathrm{PE}$ ) or because of low extinction rates (a museum of diversity, with many endemic species separated by long branches from their closest relatives; Stebbins, 1974). Thus, understanding the spatial pattern of PE and its historical and environmental drivers can help reveal the mechanisms underlying biogeographical patterns (Mishler et al., 2014).

While drivers of large-scale patterns of species diversity for multiple taxa, including plants, mammals, amphibians, birds and ants, are well known (Field et al., 2009; Hawkins et al., 2003; Stein, Gerstner, \& Kreft, 2014), how these drivers shape patterns of PE is uncertain. Areas with high species richness also tend to have high endemism, although this is not always the case (Daru, Bank, \& Davies, 2015). Mismatches between species diversity, and endemism and PE are informative, as they can reveal mechanisms that promote one but not the other. For example, islands often have high endemism but moderate species richness, indicating that geographical isolation might play an important role in promoting endemism, but in situ diversification is not rapid enough to produce high species richness (Cronk, 1997; Kier et al., 2009).

Three main categories of drivers influence patterns of species diversity and may similarly determine the distribution of (phylogenetic) endemism. First, current climatic conditions, such as mean annual precipitation, mean annual temperature and seasonality are typically important correlates of diversity (e.g., Currie, 1991; Hawkins et al., 2003). In general, more plant species are found in regions with warm, humid and aseasonal climates (e.g., Kreft \& Jetz, 2007). Second, geographical characteristics such as greater area and environmental heterogeneity, or lower geographical isolation, also increase species diversity (Stein et al., 2014). Principal among these is topographic heterogeneity (Jetz \& Rahbek, 2002; Keppel, Gillespie, Ormerod, \& Fricker, 2016). Environmental heterogeneity is assumed to drive species diversity via coexistence, promoting species persistence during unfavourable times and may increase speciation rates (Stein \& Kreft, 2015). At the same time, heterogeneity often creates dispersal barriers that may decrease species diversity but may increase speciation rates (Quintero \& Jetz, 2018). Third, historic climatic conditions including long-term climate stability and the availability of suitable habitat through time, have been found to positively affect taxonomic endemism or phylogenetic diversity (Dynesius \& Jansson, 2000; Jansson, 2003; Kissling et al., 2012; Sandel et al., 2011). There are reasons to expect a region with a long history of high tree cover 
to have high or low PE. On the one hand, areas with higher tree cover might be associated with larger range sizes per species, leading to low endemism. On the other hand, high tree cover and climatic stability over time may support higher tree species richness, providing increased opportunities for allopatric speciation and promoting the coexistence of more small-ranged species (Losos \& Schluter, 2000).

Here, we examine drivers of PE among c. 60,000 tree species on Earth (Beech, Rivers, Oldfield, \& Smith, 2017). Trees may show different patterns than other taxa, such as mammals (Rosauer \& Jetz, 2015) and grasses (Sandel, Monnet, Govaerts, \& Vorontsova, 2016), due to their long life spans, long dispersal distances, and the tolerances to frost and drought present in many tree species (Choat et al., 2012; Nathan, 2006; Zanne et al., 2014). Further, unlike mammals or grasses, trees are not a monophyletic group, but rather a growth form that has evolved and been lost numerous times (Smith \& Donoghue, 2008). Trees also provide vital ecosystem services (e.g., Gamfeldt et al., 2013) and support the biodiversity of many other taxa (e.g., Barnes et al., 2017; Staab, Schuldt, Assmann, \& Klein, 2014). Thus, describing patterns of PE and understanding their covariation with past and present environmental and geographical conditions is essential for efforts to protect existing diversity and to determine the likely importance of future threats, such as climate change.

It is difficult to predict whether historical climate, current climate or geography will be most important for explaining modern PE patterns of trees. On the one hand, the long life spans and generation times of trees slow down evolutionary processes (Smith \& Donoghue, 2008) and the dispersal of species as climate changes (Svenning \& Skov, 2004), implying that historical factors may play a large role in explaining modern patterns of PE (Feng et al., 2017; Ma, Sandel, \& Svenning, 2016; Zanne et al., 2014). On the other hand, the abilities of many tree species to disperse long distances might allow them to track their optimal environmental conditions (Kremer et al., 2012; Zanne et al., 2014), and may result in current rather than past climate conditions better predicting patterns of tree PE (Ma et al., 2016). Finally, the ability of tree species to occur across vast temperature and precipitation gradients could result in geographical characteristics, such as the range of elevations present in an area or access to glacial refugia, being important predictors of PE (Hazzi, Moreno, Ortiz-Movliav, \& Palacio, 2018; Ma et al., 2016).

\section{2 | METHODS}

\section{1 | Species data and distribution data}

The GlobalTreeSearch database (Botanic gardens conservation international (BGCl), 2017) served as the main source of tree distributions, offering country-level distribution data for 58,762 tree species. To obtain finer-grained distribution information for some large countries (USA, Canada, Mexico, Brazil, China and Australia), we replaced country-level information with sub-national tree checklists from the Global Inventory of Floras and Traits (GIFT) database (Weigelt, König, \& Kreft, 2019, data from Baker \& Duretto, 2011; Barker, Barker, Jessop, \& Vonow, 2005; Chinese
Virtual Herbarium, 2016; CONABIO, 2016; Jardim Botânico do Rio de Janeiro, 2016; Royal Botanic Gardens \& Domain Trust, 2017; Queensland Government, 2014; Short, Albrecht, Cowie, Lewis, \& Stuckey, 2011; USDA NRCS, 2015; VicFlora, 2016; Western Australian Herbarium, 2017) leading to a global dataset of tree checklists for 463 geographical regions worldwide. GIFT includes regional plant checklists from published Floras and checklists as well as information on functional traits like growth form extracted from the included floras as well as large global trait databases. In order to combine GlobalTreeSearch and GIFT data, we processed species names from GlobalTreeSearch with the same taxonomic standardization procedure as applied for all species in GIFT (see Weigelt et al., 2019), which led to a set of 58,258 taxonomically standardized species names in the GlobalTreeSearch data. Replacing large countries from the GlobalTreeSearch database with smaller entities from GIFT resulted in a loss of 663 species that were not covered by the small-scale checklists from GIFT. At the same time, the checklists from GIFT included 947 tree species not covered by GlobalTreeSearch, leading to a final dataset with 58,542 tree species. To apply a definition of trees as similar as possible among the two datasets, we removed tree species from GIFT that were not included in GlobalTreeSearch if other trait data in GIFT included conflicting trait information (non-woody tissue, obligate epiphytic or climbing habit, or plant height below $2 \mathrm{~m}$ ), if less than $70 \%$ of the resources in GIFT agreed on the growth form being tree, and if no members of the given plant family were included in GlobalTreeSearch (e.g., cycads, tree ferns, grass trees or bamboos).

Trees are a relatively well-studied group and the GlobalTreeSearch data represent the most comprehensive attempt to date to compile their distribution information. Nevertheless, some regions and taxa may be undersampled. Some areas with high species richness, such as Southeast Asia, have not been extensively surveyed and are therefore probably still somewhat undersampled. Other biodiverse countries including Colombia, Brazil and China have more up-todate species lists that are likely to be more complete (Beech et al., 2017). Any estimate of the numbers of missing species in less-sampled countries would be very imprecise, and it is still more difficult to know how these missing species would change the $\mathrm{PE}$ of a region (because it is unknown where on the phylogeny these species would occur). We explored a possible role of sampling bias by mapping the residuals of models predicting species richness and $\mathrm{PE}$ from a set of climate variables (see below for variables and model details), and assessing whether the residuals were associated with regions of suspected undersampling.

\section{2 | Phylogeny}

We used a large, dated phylogeny of seed plants with 353,185 tips from Smith and Brown (2018) as a backbone to build a phylogeny of all species in the dataset. We conservatively bound species into the backbone using dating information from congeners in the tree using 'congeneric.merge' in the R package 'pez' (Pearse et al., 2015). 


\section{3 | Phylogenetic endemism}

We used a variant of Rosauer et al.'s (2009) PE (Myr/ $\left.\mathrm{km}^{2}\right)$. Our approach builds on the R function phyloendemism() in the PDcalc package by $\mathrm{D}$. Nipperess. The PE of a region is the total phylogenetic branch length encompassed by species in that region, where the phylogeny is modified such that each branch length is divided by the global range size of its descendent clade. The original function computes range size for each species as the number of regions where it occurs. We updated it to estimate range size as the total area of all regions where a species occurs, to account for widely varying region size in our dataset. For comparison, we also computed PE values based on counts of regions occupied, which was fairly well correlated with our measure of area-based PE $(r=.71)$.

Our implementation also differs in being an unrooted measure of PE. This means that the measure of PE includes the branch length to the root of the tree only if the root node lies on the path between two tips in the sample. We prefer this unrooted version, since it is insensitive to arbitrarily making the tree deeper via the inclusion of an outgroup.

\subsection{Ancillary metrics of diversity and endemism}

Patterns of PE are ultimately driven by a combination of both taxonomic endemism and phylogenetic uniqueness. To improve our ability to interpret PE, we therefore computed measures of phylogenetic and non-phylogenetic diversity and endemism that relate to these two components. The diversity metrics were species richness (S) and the rarified phylogenetic diversity index (rarPDI, Sandel, 2018). rarPDI is derived from Faith's (1992) unrooted phylogenetic diversity (PD) and its richness-standardized variant, the phylogenetic diversity index (PDI, Tsirogiannis \& Sandel, 2016). PDI is calculated as the standardized effect size of the PD, relative to the expectation and variance of $\mathrm{PD}$ for a random draw of $\mathrm{S}$ species from the tree, where $S$ is the species richness of the assemblage. PDI is dependent on species richness in the presence of a phylogenetic selection process (such as environmental filtering, Sandel, 2018). Therefore, we also calculated rarPDI by rarefying the region-by-species matrix to 100 species per region and computing PDI on this matrix. We repeated this rarefaction 100 times, and used the mean across replicates. We calculated rarPDI using the $\mathrm{R}$ package PhyloMeasures (Tsirogiannis \& Sandel, 2016). Positive rarPDI values indicate higher PD than is expected under a null model (i.e., phylogenetic overdispersion), while negative values indicate lower than expected PD (i.e., phylogenetic clustering).

For taxonomic endemism, we calculated range size rarity [RSR, sum(1/range size) for all species in a region]. In the special case of a star phylogeny (i.e., all species form a single polytomy), RSR is equivalent to PE. PE and RSR were highly correlated ( $r=.95$ ), so we also calculated the residuals of an ordinary regression of PE against RSR to identify the regions that have unusual PE values given their RSR. We call this the PE index, or PEI.

\section{5 | Predictor variables}

For each region, we considered a range of candidate variables that have been shown or hypothesized to relate to tree diversity and/ or endemism. Broadly, these can be classified into three groups. The first group (Geographical variables) described the geographical context. This group included the area of the region (AREA; in $\mathrm{km}^{2}$ ), the maximum range of elevations found within the region (ELEV_ RANGE; in $\mathrm{m}$ ), and the proportion of landmass relative to open water surrounding each region summed up for buffer distances of 100 , 1,000 and $10,000 \mathrm{~km}$ around the focal region [surrounding landmass proportion (SLMP); unitless; Weigelt \& Kreft, 2013]. SLMP serves as a measure of potential source areas for colonization. It is highest for regions located in the centre of large continents and lowest for isolated islands. The second group (Climatic variables) described modern climate. We used four variables to describe the mean and seasonality of temperature and precipitation [annual mean temperature (TEMP; ${ }^{\circ} \mathrm{C}$ ); annual precipitation (PREC; $\mathrm{mm} / \mathrm{yr}$ ); standard deviation of mean monthly temperatures (VAR_TEMP; ${ }^{\circ} \mathrm{C}$ ); coefficient of variation in monthly precipitation (VAR_PREC; unitless); Karger et al., 2017]. These variables were calculated as described by Weigelt, Jetz, and Kreft (2013). Finally, we used four variables (Historical variables) to describe historical climate and vegetation dynamics. These were the velocity of temperature change since the Last Glacial Maximum (LGM; VELOCITY; m/yr, following Sandel et al., 2011 but based on $1-\mathrm{km}^{2}$ resolution input rasters) and estimates of cover of woody vegetation types at present (Olson et al., 2001), the LGM (Ray \& Adams, 2001), Pliocene (PRISM4 Paleoenvironmental Reconstruction, 2016) and Middle Miocene (Henrot et al., 2010) (CURR_TREES, LGM_ TREES, PLIO_TREES, MIO_TREES, respectively; proportion tree cover). These estimates are based on palaeoclimate reconstructions combined with palaeovegetation records. These four time points describe the expansion and contraction of woody vegetation types over time.

\section{6 | Regions}

We performed separate analyses for mainland and island regions. Two factors motivated this decision: first, the factors that drive diversity and endemism may differ between islands and mainlands (Kier et al., 2009) and second, estimates of past tree cover were generally not available for islands, requiring us to omit those variables from all models including islands.

To examine how the effects of geographical, climatic and historical variables on PE varied among regions with different biogeographical histories, we further divided mainland regions into the four major floristic kingdoms (Australis, Holarktis, Neotropis, Paleotropis), following Good (1947), as updated by Takhtajan (1986). We excluded the kingdoms of Antarktis (no tree species) and merged the Capensis with the Paleotropis because this kingdom is much smaller than the other kingdoms and smaller than the country of South Africa for which we have tree distribution data. All analyses were repeated within these kingdoms. 


\section{7 | Analysis}

We fit ordinary linear regression models to explain variation in the response variables (mainly PE, see SI for S, RSR, PD, PDI, rar$\mathrm{PDI}$ and $\mathrm{PEI}$ ) using all predictor variables, with regions as replicates (total $N=463$ ). In most cases, there was little residual spatial autocorrelation. However, some autocorrelation remained in certain cases, so we also fit error simultaneous autoregressive models (Kissling \& Carl, 2008) with a neighbourhood of $1,000 \mathrm{~km}$, which successfully removed autocorrelation over the smallest distance classes. In all cases, we report standardized regression coefficients. Multicollinearity was not a major issue in our analyses as predictor variables were not strongly collinear and all variance inflation factors (VIFs) were $<5$, sample sizes were large ( $n=335$ for mainlands, $n=93$ for islands) and the residual variances for most models were relatively low (Morrisey \& Ruxton, 2018).

We then repeated this process within the four floristic kingdoms. Within these kingdoms, the predictor variables sometimes exhibited high multicollinearity. In particular, VIF was greater than 10 for TEMP in the Australis, and $>5$ for PREC, VAR_TEMP, VAR_PREC and SLMP in the Australis, PREC in the Neotropis and PREC and CURRENT_TREES in Paleotropis. Thus, these regression coefficients are expected to have higher uncertainty, although neither their estimates nor their standard errors are biased as a result (Morrissey \& Ruxton, 2018).

Finally, we used variance partitioning to ascribe the explanatory power of the linear models to each of the three groups of variables or to their overlaps. We did not do variance partitioning for islands, since most historical variables had to be omitted from models for islands.

Prior to regression analyses, we transformed our variables to meet normality assumptions as follows: S, PD, RSR and PE were logtransformed. PREC and VAR_TEMP were square root-transformed, and VELOCITY, AREA and ELEV_RANGE were log-transformed.
All analyses were conducted in R (R Core Team, 2017), using the raster (Hijmans, 2017), sp (Pebesma \& Bivand, 2005) and spdep (Bivand \& Piras, 2015) packages.

\section{3 | RESULTS}

Phylogenetic endemism (PE) was highest in tropical regions and on islands (Figure 1). Among mainland regions, there was a notable asymmetry between the Northern and the Southern Hemispheres, with more modest declines in PE with increasing latitude in the south, and more marked decreases in the north. Among all mainland regions, Costa Rica had the highest PE, while Lord Howe Island had the highest PE among islands (Tables 1 and 2).

Two geographical variables, connectivity (surrounding landmass proportion, SLMP) and elevational range (ELEV_RANGE), were the only consistently significant predictors of PE for both island and mainland regions (Figure 2). Surrounding landmass had the most consistent influence, with a negative effect on $\mathrm{PE}$ (Figure 2), that is, higher PE in more isolated regions. Among all mainland regions, all islands and within three of the four mainland kingdoms (all except Holarctis), increasing connectivity decreased PE. PE increased with elevational range (ELEV_RANGE) among all mainlands and especially among island regions. In addition, area had a negative and mean annual temperature a positive relationship with PE on islands, while for mainland regions temperature seasonality was a negative predictor.

Floristic kingdoms differed in historic and current climate explanatory variables that were significant predictors of PE (Figure 2). Historical cover by forests had modest but significant influences on PE among mainland areas in tropical regions only. The influence of historical forest cover depended on the time period. Regions with high current tree cover generally had higher PE, but this relationship was only significant for the Neotropis. High tree cover deeper (a)

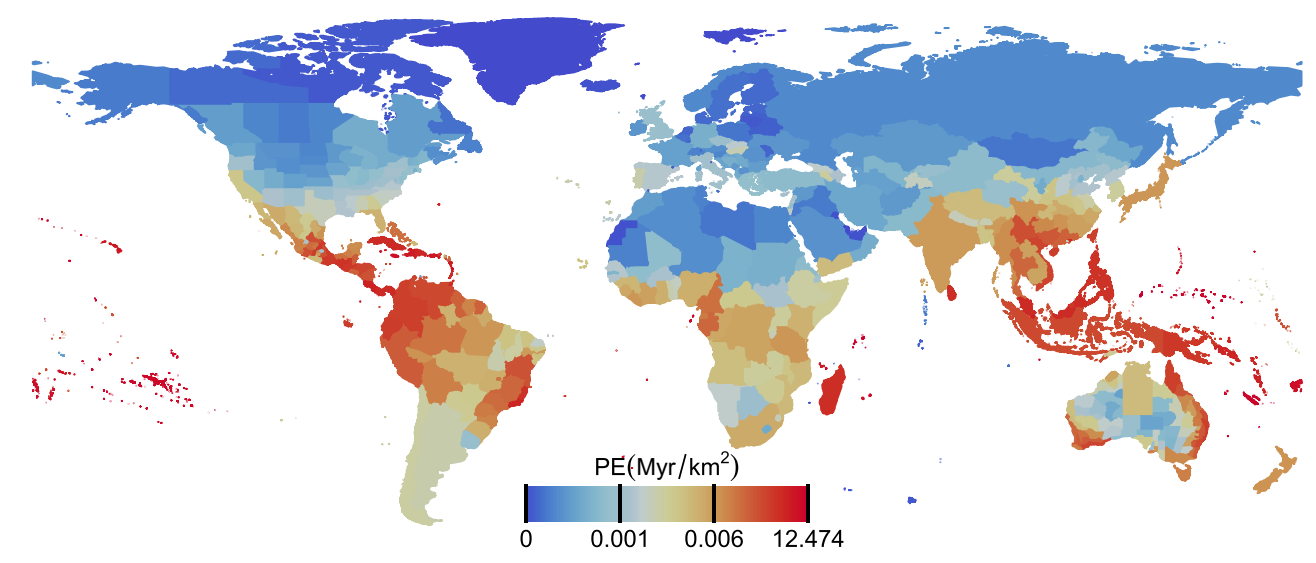

(b)

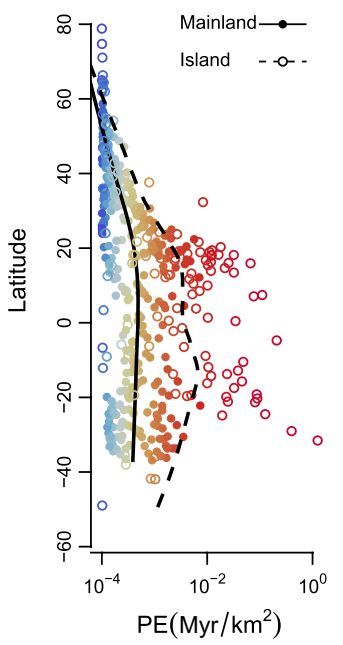

FIGURE 1 Global patterns of phylogenetic endemism (PE; Myr $/ \mathrm{km}^{2}$ ) of trees $(n=58,542$ tree species) across 463 countries and other administrative units. The map (a) colour scale is based on percentile-transformed values. In (b), the fitted lines are lowess regressions, separately fitted for island and mainland regions [Colour figure can be viewed at wileyonlinelibrary.com] 


\begin{tabular}{|c|c|c|c|c|c|}
\hline Region & Species & Region & PE & Region & PEI \\
\hline Colombia & 5,750 & Costa Rica & 0.100 & $\begin{array}{l}\text { Esperance Plains, } \\
\text { Australia }\end{array}$ & 0.423 \\
\hline Malaysia & 4,946 & $\begin{array}{l}\text { Rio de Janeiro, } \\
\text { Brazil }\end{array}$ & 0.073 & Warren, Australia & 0.395 \\
\hline Venezuela & 4,652 & Panama & 0.070 & Mallee, Australia & 0.393 \\
\hline Peru & 4,456 & Malaysia & 0.061 & Jarrah Forest, Australia & 0.365 \\
\hline Amazonas & 4,132 & $\begin{array}{l}\text { Hong Kong } \\
\text { (State) }\end{array}$ & 0.056 & Distrito Federal, Brazil & 0.356 \\
\hline Ecuador & 3,590 & Chiapas, Mexico & 0.047 & $\begin{array}{l}\text { Swan Coastal Plain, } \\
\text { Australia }\end{array}$ & 0.349 \\
\hline Yunnan & 3,016 & $\begin{array}{l}\text { Espirito Santo, } \\
\text { Brazil }\end{array}$ & 0.040 & $\begin{array}{l}\text { Geraldton Sandplains, } \\
\text { Australia }\end{array}$ & 0.319 \\
\hline Bolivia & 2,986 & Oaxaca, Mexico & 0.040 & $\begin{array}{l}\text { Southern Tablelands, } \\
\text { Australia }\end{array}$ & 0.314 \\
\hline Pará, Brazil & 2,737 & $\begin{array}{l}\text { Guerrero, } \\
\text { Mexico }\end{array}$ & 0.039 & $\begin{array}{l}\text { Northern Tablelands, } \\
\text { Australia }\end{array}$ & 0.310 \\
\hline Panama & 2,663 & Guatemala & 0.037 & $\begin{array}{l}\text { Central Tablelands, } \\
\text { Australia }\end{array}$ & 0.304 \\
\hline
\end{tabular}

TABLE 1 The top 10 mainland regions for tree species richness, phylogenetic endemism (PE) and phylogenetic endemism index (PEI)

TAB LE 2 The top 10 island regions for tree species richness, phylogenetic endemism (PE) and phylogenetic endemism index (PEI)

\begin{tabular}{lllrll} 
Region & Species & Region & PE & Region & PEI \\
\hline Indonesia & 5,181 & Lord Howe Island & 12.474 & United States Minor Outlying Islands & 0.564 \\
\hline Madagascar & 3,215 & Norfolk Island & 3.998 & Guam & 0.479 \\
\hline Papua New Guinea & 2,586 & Seychelles & 2.084 & Kiribati & 0.404 \\
\hline Philippines & 2,197 & Pitcairn Islands & 1.262 & Christmas Island & 0.404 \\
\hline New Caledonia & 1,467 & Palau & 1.107 & Kangaroo Island & 0.364 \\
\hline Hainan & 1,326 & Mauritius & 0.893 & Cook Islands & 0.343 \\
\hline Cuba & 1,317 & Cook Islands & 0.870 & Seychelles & 0.329 \\
\hline Haiti & 1,046 & New Caledonia & 0.811 & Tasmania & 0.280 \\
\hline Dominican Republic & 1,027 & Micronesia & 0.763 & New Caledonia \\
\hline Sri Lanka & 855 & United States Minor Outlying Islands & 0.663 & Norfolk Island \\
\hline
\end{tabular}

in history (Miocene) was associated with lower PE for Neotropis, and high tree cover during the LGM was related to higher PE for Paleotropis. The velocity of temperature change from the LGM to present had no significant association with PE.

Current climate also exerted strong controls on PE (Figure 2). Among mainlands, low temperature seasonality (VAR_TEMP) was the main predictor of high PE for Holarctis and Neotropis, while low precipitation seasonality was an important predictor in Paleotropis. In three of the four mainland kingdoms (all but Neotropis), higher annual precipitation was associated with higher PE.

Variance partitioning revealed that nearly equal proportions of variance were explained among the three predictor variable groups. Each group uniquely explained between 8 and $10 \%$ of the variance in PE. Climate and historical predictors shared the largest fraction of variance explained (12\%) and a further $12 \%$ of the variance explained was shared across all three predictor variable groups. In total, $65 \%$ of the variance in $\mathrm{PE}$ was explained by these predictor variables.

We considered a range of other biogeographical patterns in trees, including species richness, taxonomic endemism and PD (Supporting
Information Figures S1-S8). Overall, geographical patterns of PE and range size rarity were nearly indistinguishable (RSR; $r=.99$, Figure 3 , Supporting Information Figures S1, S6). PE was also highest in areas with high species richness $(r=.39)$, high PD $(r=.41)$ and high rarPDI $(r=.35$, all $p<.001)$, but these correlations were only moderate. To attempt to isolate the effect of phylogenetic uniqueness on PE from the strong effect of species range size, we calculated the residuals of the regression of PE on RSR, that is, the phylogenetic endemism index (PEI). PEI showed little variation across latitudes, but revealed high PE for a given RSR (i.e., demonstrating high phylogenetic uniqueness) in some regions including southern South America, East and Southern Asia, eastern and south-western Australia and western Africa (Figure 3, Table 1). Across mainland regions, $\mathrm{PEI}$ was highest in large regions with high tree cover during the LGM, and low climate change velocities (Supporting Information Figure S8). Among islands, PEI decreased with increasing elevational range. Historical variables explained the largest unique fraction of the variance in PEI, with nearly no overlapping explanations from the three variable groups (Supporting Information Figure S8). 
(a) Global

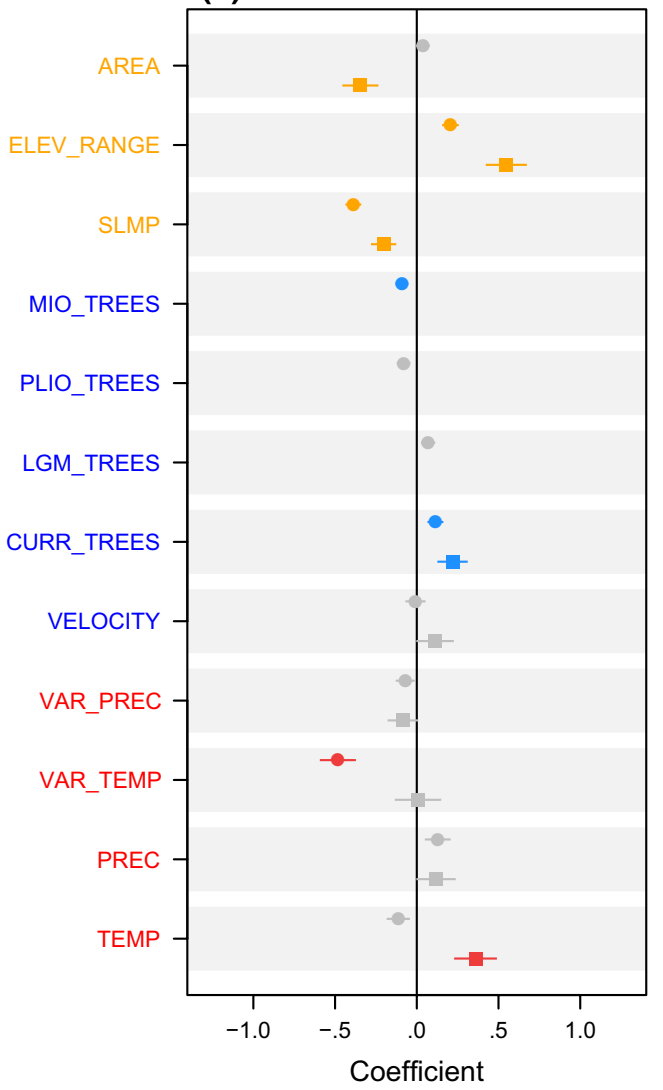

(b) Kingdoms

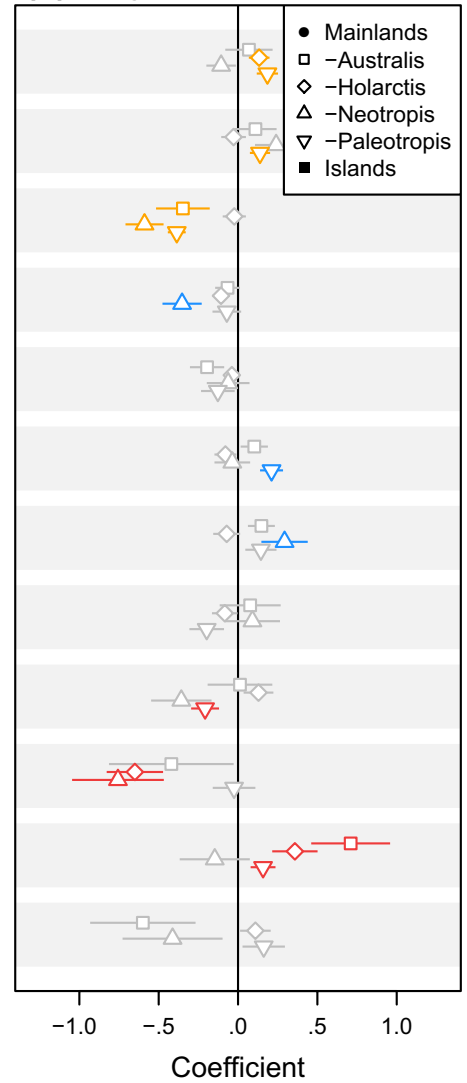

FIGURE 2 Standardized regression coefficients from multiple simultaneous autoregressive models for phylogenetic endemism of trees for (a) global mainland and island regions and (b) the four major floristic kingdoms excluding islands. Bars around each point show the standard error of the coefficient estimate. Significant geographical, historical and climate variables are indicated in orange, blue and red, respectively. Non-significant explanatory variables $(p>.05)$ are indicated in grey. AREA $=$ area of the region; ELEV_RANGE $=$ elevational range; SLMP = surrounding landmass proportion; MIO_TREES = Middle Miocene tree cover proportion; PLIO_TREES = Pliocene tree cover proportion; LGM_TREES = Last Glacial Maximum tree cover proportion; CURR_TREES = present tree cover proportion; VELOCITY = velocity of temperature change since the Last Glacial Maximum; VAR_PREC = coefficient of variation in monthly precipitation; VAR_TEMP = standard deviation of mean monthly temperatures; PREC = annual precipitation; TEMP = annual mean temperature [Colour figure can be viewed at wileyonlinelibrary.com]

Maps of residuals of species richness and PE identified regions that are known biodiversity hotspot anomalies, including South Africa and Madagascar, but did not suggest dramatic undersampling in Southeast Asia or Sub-Saharan Africa (Supporting Information Figure S9). Thus, while the GlobalTreeSearch data are certainly incomplete, we do not see evidence for strong spatial biases in the tree inventory completeness.

\section{4 | DISCUSSION}

Our analysis of the world's trees reveals that PE varies by orders of magnitude, is higher on islands than mainlands, is explained almost equally by geographical, historical and current factors, and is highly correlated with taxonomic endemism. While some geographical variables (especially connectivity and elevational range) appear to consistently predict PE, the effect of historic and current climate variables differs considerably among the floristic kingdoms. PE is highly correlated with RSR, showing that it is driven primarily by variation in range size rather than evolutionary uniqueness.

As expected, geographical factors strongly influence $\mathrm{PE}$, with isolation and topographic heterogeneity promoting endemism. Being isolated from regions with similar climatic conditions likely promotes endemism by supporting a diversity of species with small range sizes and preventing biotic exchange. Hence, isolation results in high observed PE of trees on islands relative to mainland regions and also higher PE in mainland regions that are less strongly embedded in continental landmass (e.g., coastal regions or peninsulas, Taylor \& Regal, 1978). Similarly, topographic heterogeneity creates a diverse array of small habitat patches that simultaneously support high species richness and small range sizes (McFadden et al., 2019). These results are consistent with previous results for plants and animals that have focused on taxonomic endemism (Kier et al., 2009; Ohlemüller et al., 2008; Sandel et al., 2011). 
(a) Range size rarity (RSR)

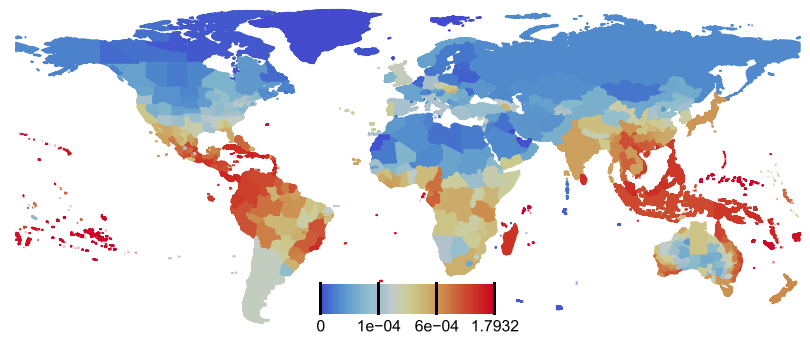

(b) Phylogenetic endemism index (PEI)

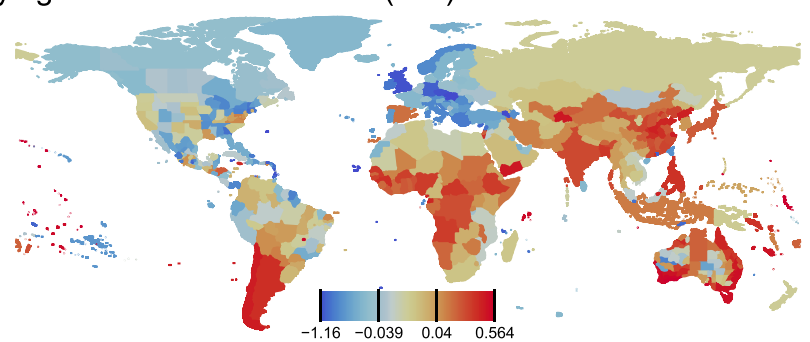

(c) RSR-PE relationship

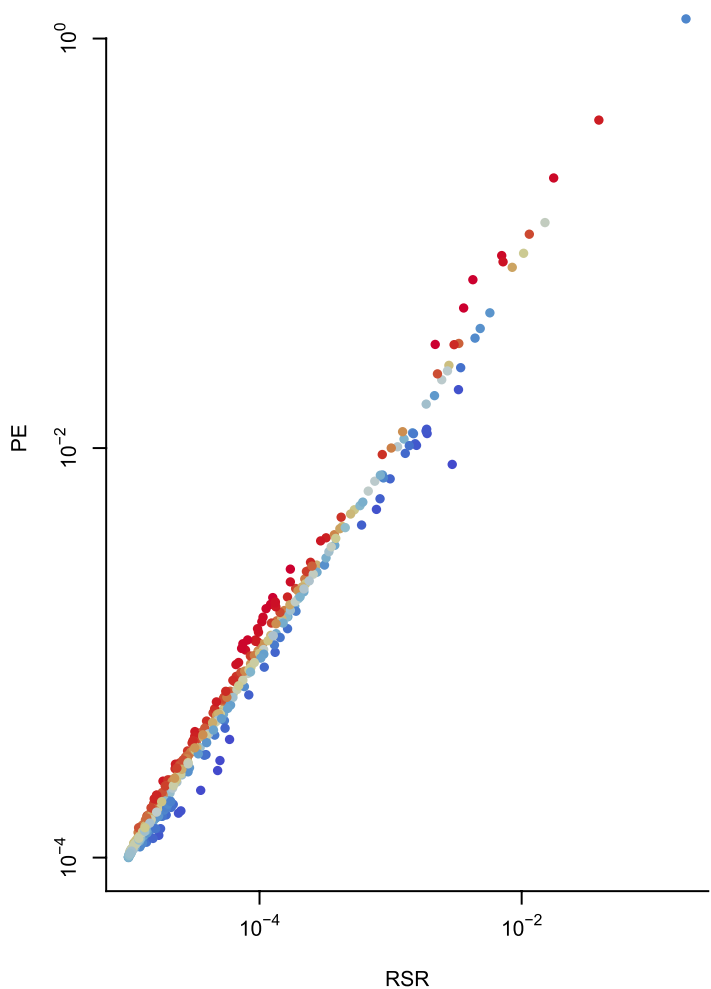

FIGURE 3 Global patterns of taxonomic endemism measured as range size rarity [RSR (per $\mathrm{km}^{2}$ ), a] and the phylogenetic endemism index (PEI, b) derived from the residuals of the RSR-PE relationship (c) [Colour figure can be viewed at wileyonlinelibrary.com]

In mainland regions, $\mathrm{PE}$ is highest near the equator and declines steeply away from the equator in the Northern Hemisphere but mildly in the Southern Hemisphere. The strong decline in PE to the north could reflect the increasing land area and correspondingly larger range sizes of tree species. Land area in the Southern Hemisphere declines towards the pole, producing smaller ranges and higher endemism. This is consistent with results from birds, in which range sizes are strongly correlated with the availability of land in latitudinal bands (Orme et al., 2006). At any given latitude, the PE of islands is higher than on mainlands most likely because of strong effects of geographical isolation. This supports previous results for taxonomic endemism of vascular plants by Kier et al. (2009).

We expected that habitat availability through time could positively or negatively relate to $\mathrm{PE}$, with high habitat area possibly leading to larger range sizes, but also greater potential for allopatric speciation. We found that $\mathrm{PE}$ is positively associated with current tree cover, suggesting that the net effect of tree cover might be higher tree endemism. However, intriguingly, historic tree cover during the Miocene, Pliocene and LGM usually did not have a significant positive influence on endemism (except a positive influence of LGM tree cover on PE within the Palaeotropics). Instead, Miocene tree cover had a negative influence on both RSR and PE, globally and especially within the Neotropics. This suggests that long periods of high tree cover might have promoted species range extensions, thus overwhelming the positive influence of recent tree cover.
The negative effect of Miocene tree cover on PE was particularly important in Neotropis. This could reflect the fact that the Miocene was a geologically dynamic period for Neotropis, with substantial uplift of the Andes and associated rearrangement of the major river networks (Hoorn, Guerrero, Sarmiento, \& Lorente, 1995). These events likely promoted diversification in South America (Hughes, Pennington, \& Antonelli, 2012). North and Central America were separated from South America throughout the Miocene and had relatively low tree cover. Since the Miocene, Central America has developed high tree cover and endemism, but many plant lineages in modern Central America have their origins in South America [e.g., members of Malpighiaceae (Willis, Franzone, Xi, \& Davis, 2014)].

Tree cover during the LGM emerged as a particularly important predictor in Paleotropis. Because of the cold global climate during the LGM most regions in Africa experienced a substantial decrease in tree cover (Couvreur, 2014). This contraction may be linked to higher extinction rates of palms in that region (Kissling et al., 2012). On the other hand, Southeast Asia experienced a relatively stable climate, maintaining high tree cover through the LGM and promoting high endemism (Feng, Mao, Sandel, Swenson, \& Svenning, 2016). Perhaps because of this historical idiosyncrasy, tree PE today is unevenly distributed across Paleotropis, being much higher in Southeast Asia than Africa.

Climate change velocity since the LGM did not significantly explain current tree PE for any region or floristic kingdom. However, more unstable climates (higher velocities) harbour less PE than expected given their taxonomic endemism (i.e., climate velocity was 
negatively associated with PEI on mainlands). This suggests that environmental filtering is occurring in areas with rapidly changing climate, such that only certain clades can migrate fast enough to keep pace with the change (Ma et al., 2016; Qian \& Sandel, 2017; Svenning, Eiserhardt, Normand, Ordonez, \& Sandel, 2015). Historical factors explained more of the variance of PEI than geographical and current climate factors, supporting the idea that historical variables play an important role in driving variation in phylogenetic distinctiveness.

Current climate influenced global patterns of PE as expected, with high temperature and precipitation and low seasonal variation in temperature and precipitation promoting endemism. Australia is an interesting case, in which current precipitation was an overwhelmingly strong predictor of $\mathrm{PE}$. This may reflect the fact that arid conditions in Australia have developed fairly recently, with wet and warm conditions dominating until the mid-Miocene. Aridification became particularly severe about $4 \mathrm{Ma}$ (Byrne, 2008). Thus, most Australian lineages are ancestrally adapted to wetter conditions (Byrne et al., 2011), and, as evolutionary transitions from wet to dry conditions are rare (Crisp et al., 2009), these older lineages are now primarily restricted to the wet portions of the country. This would suggest that arid regions are unusually species-poor in Australis compared to wetter regions, which is indeed the case. The two distinct hotspots in Australia - one in the arid southwest and one on the wet east coast - include many phylogenetically distinct and small-ranged species, supporting the finding that modern climatic conditions act as a strong filter on species' capacity to escape or tolerate drought conditions (Choat et al., 2012).

The PE pattern observed for trees is similar in many respects to that of mammals (Rosauer \& Jetz, 2015). Both groups show latitudinal gradients with particular declines in PE towards the north. Furthermore, mammal PE appears to be influenced by a combination of current climate, historical conditions and geographical context (especially isolation), just as we found for trees. In part, this likely reflects shared biogeographical histories and ecological factors that similarly shape patterns in these two groups. On the other hand, it might also reflect a functional reliance of many mammal species on trees, whereby the biogeographical patterns of trees drive parallel patterns in other groups, likely also including other groups as well, such as insects (Novotny et al., 2006) and amphibians (Vie, HiltonTaylor, \& Stuart, 2009). The relationship between taxonomic endemism and PE was stronger for trees than for mammals, perhaps because mammals, unlike trees, are a phylogenetic clade.

Our set of tree species included both angiosperms and gymnosperms, and it is possible that the patterns of PE would be strongly driven by the presence or absence of a few gymnosperm species, which are deeply divergent from the angiosperms. However, gymnosperms made up only c. $1 \%$ of the tree species, and the nature of PE as a PD-like measure means that it is weighted towards the most species rich groups. We calculated PE for just angiosperms and just gymnosperms (Supporting Information Figure S10), and found that angiosperm PE was very well correlated with that for all trees $(r=.995)$ and reasonably well correlated with that of gymnosperms $(r=.543)$
Our findings have important implications for conservation. We need to prioritize conservation efforts on the current hotspots that support high PE, due to historic, geographical and current climate factors. Endemic species of trees, as well as other taxonomic groups, tend to be associated with small habitat patches that support high species richness and small range sizes (e.g., islands and mainland peninsulas), and conservation of these small areas of land would disproportionately benefit global tree conservation. We find that PE is positively associated with proximity to the equator and current tree cover, and thus, our results reinforce the conservation urgency for the vast Neotropical forests of Central and South America. In regions such as Australis, where tree species is highly associated with current climate, climate change is an acute threat, and unique species within rapidly changing regions should be prioritized for ex situ conservation.

\section{ACKNOWLEDGMENTS}

We thank the $\mathrm{BGCl}$ and its members for making available the data on the global distributions of trees. Funding was provided by the Alexander von Humboldt Foundation in the framework of the Alexander von Humboldt Professorship and by the Helmholtz Recruitment Initiative of the Helmholtz Association (both to TMK). GK was partially supported by an Alexander von Humboldt Foundation fellowship. MTvdS is supported by the Rubicon research programme with project number $019.171 \mathrm{LW} .023$, which is financed by the Netherlands Organisation for Scientific Research (NWO).

\section{DATA AVAILABILITY STATEMENT}

All data at the country level are available as a GIS shapefile at doi: 10.5061/dryad.jn07s0s.

\section{ORCID}

Brody Sandel iD https://orcid.org/0000-0003-2162-6902

Masha T. van der Sande (iD https://orcid.org/0000-0002-6845-2308

Dylan Craven (iD https://orcid.org/0000-0003-3940-833X

\section{REFERENCES}

Baker, M. L., \& Duretto, M. F. (2011). A census of the vascular plants of Tasmania. Hobart, Australia: Tasmanian Herbarium, Tasmanian Museum and Art Gallery.

Barker, W. R., Barker, R. M., Jessop, J. P., \& Vonow, H. P. (2005). Census of South Australian vascular plants. Journal of the Adelaide Botanic Gardens Supplement, 1, 1-396.

Barnes, A. D., Allen, K., Kreft, H., Corre, M. D., Jochum, M., Veldkamp, E., ... Brose, U. (2017). Direct and cascading impacts of tropical land-use change on multi-trophic biodiversity. Nature Ecology and Evolution, 1(10), 1511-1519. https://doi.org/10.1038/s41559-017-0275-7

Beech, E., Rivers, M., Oldfield, S., \& Smith, P. (2017). GlobalTreeSearch: The first complete global database of tree species and country distributions. Journal of Sustainable Forestry, 36(5), 454-489. https://doi. org/10.1080/10549811.2017.1310049 
BGCl. (2017). GlobalTreeSearch online database. Richmond, UK: Botanic Gardens Conservation International. Retrieved from www.bgci.org/ globaltree_search.php

Bivand, R., \& Piras, G. (2015). Comparing implementations of estimation methods for spatial econometrics. Journal of Statistical Software, 63(18), 1-36.

Byrne, M. (2008). Evidence for multiple refugia at different time scales during Pleistocene climatic oscillations in southern Australia inferred from phylogeography. Quaternary Science Reviews, 27(27-28), 2576-2585.

Byrne, M., Steane, D. A., Joseph, L., Yeates, D. K., Jordan, G. J., Crayn, D., ... Keogh, J. S. (2011). Decline of a biome: Evolution, contraction, fragmentation, extinction and invasion of the Australian mesic zone biota. Journal of Biogeography, 38(9), 1635-1656.

Chinese Virtual Herbarium. (2016). The Flora of China v. 5.0. Beijing, China: Chinese Academy of Sciences. Retrieved from http://www. cvh.org.cn/, checked on 15 January 2016.

Choat, B., Jansen, S., Brodribb, T. J., Cochard, H., Delzon, S., Bhaskar, R., ... Zanne, A. E. (2012). Global convergence in the vulnerability of forests to drought. Nature, 491(7426), 752-755. https://doi. org/10.1038/nature11688

CONABIO. (2016). Sistema Nacional de Información sobre Biodiversidad. Mexico City: Author. Retrieved from https://www.gob.mx/conabio, checked on 4/11/2016.

Couvreur, T. L. P. (2014). Odd man out: Why are there fewer plant species in African rain forests? Plant Systematics and Evolution, 301(5), 1299-1313. https://doi.org/10.1007/s00606-014-1180-z

Crisp, M. D., Arroyo, M. T., Cook, L. G., Gandolfo, M. A., Jordan, G. J., McGlone, M. S., ... Linder, H. P. (2009). Phylogenetic biome conservatism on a global scale. Nature, 458(7239), 754.

Cronk, Q. C. B. (1997). Islands: Stability, diversity, conservation. Biodiversity and Conservation, 6(3), 477-493.

Currie, D. J. (1991). Energy and large-scale patterns of animal-and plantspecies richness. The American Naturalist, 137(1), 27-49. https://doi. org/10.1086/285144

Daru, B. H., van der Bank, M., \& Davies, T. J. (2015). Spatial incongruence among hotspots and complementary areas of tree diversity in southern Africa. Diversity and Distributions, 21(7), 769-780. https:// doi.org/10.1111/ddi.12290

Dynesius, M., \& Jansson, R. (2000). Evolutionary consequences of changes in species' geographical distributions driven by Milankovitch climate oscillations. Proceedings of the National Academy of Sciences USA, 97(16), 9115-9120.

Faith, D. P. (1992). Conservation evaluation and phylogenetic diversity. Biological Conservation, 61(1), 1-10. https://doi. org/10.1016/0006-3207(92)91201-3

Feng, G., Ma, Z., Benito, B. M., Normand, S., Ordonez, A., Jin, Y., ... Svenning, J. C. (2017). Phylogenetic age differences in tree assemblages across the Northern Hemisphere increase with long-term climate stability in unstable regions. Global Ecology and Biogeography, 26(9), 1035-1042. https://doi.org/10.1111/geb.12613

Feng, G., Mao, L., Sandel, B., Swenson, N. G., \& Svenning, J. C. (2016). High plant endemism in China is partially linked to reduced glacialinterglacial climate change. Journal of Biogeography, 43(1), 145-154. https://doi.org/10.1111/jbi.12613

Field, R., Hawkins, B. A., Cornell, H. V., Currie, D. J., Diniz-Filho, J. A. F., Guégan, J. F., ... O'Brien, E. M. (2009). Spatial species-richness gradients across scales: A meta-analysis. Journal of biogeography, 36(1), 132-147.

Gamfeldt, L., Snäll, T., Bagchi, R., Jonsson, M., Gustafsson, L., Kjellander, P., ... Bengtsson, J. (2013). Higher levels of multiple ecosystem services are found in forests with more tree species. Nature Communications, 4, 1340. https://doi.org/10.1038/ncomms2328

Good, R. (1947). The geography of flowering plants. London, UK: Longmans, Green and Co.
Harrison, S., \& Noss, R. (2017). Endemism hotspots are linked to stable climatic refugia. Annals of Botany, 119(2), 207-214.

Hawkins, B. A., Field, R., Cornell, H. V., Currie, D. J., Guégan, J.-F., Kaufman, D. M., ... Turner, J. R. G. (2003). Energy, water, and broadscale geographic patterns of species richness. Ecology, 84(12), 31053117. https://doi.org/10.1890/03-8006

Hazzi, N. A., Moreno, J. S., Ortiz-Movliav, C., \& Palacio, R. D. (2018). Biogeographic regions and events of isolation and diversification of the endemic biota of the tropical Andes. Proceedings of the National Academy of Sciences USA, 115(31), 7985-7990. https://doi. org/10.1073/pnas.1803908115

Henrot, A.-J., Francois, L., Favre, E., Butzin, M., Ouberdous, M., \& Munhoven, G. (2010). Effects of $\mathrm{CO}_{2}$, continental distribution, topography and vegetation changes on the climate of the Middle Miocene: A model study. Climate of the Past, 6(5), 675-694.

Hijmans, R. J. (2017). raster: Geographic data analysis and modeling. R package version 2.6-7. Retrieved from https://CRAN.R-project.org/ package $=$ raster

Hoorn, C., Guerrero, J., Sarmiento, G. A., \& Lorente, M. A. (1995). Andean tectonics as a cause for changing drainage patterns in Miocene northern South America. Geology, 23(3), 237-240. https://doi. org/10.1130/0091-7613(1995)023<0237:ATAACF>2.3.CO;2

Hrdina, A., \& Romportl, D. (2017). Evaluating global biodiversity hotspots - Very rich and even more endangered. Journal of Landscape Ecology, 10(1), 108-115.

Hughes, C. E., Pennington, R. T., \& Antonelli, A. (2012). Neotropical plant evolution: Assembling the big picture. Botanical Journal of the Linnean Society, 171(1), 1-18.

Jansson, R. (2003). Global patterns in endemism explained by past climatic change. Proceedings of the Royal Society B: Biological Sciences, 270(1515), 583-590.

Jardim Botânico do Rio de Janeiro. (2016). Flora do Brasil 2020 em construção. Retrieved from http://floradobrasil.jbrj.gov.br/, checked on $5 / 9 / 2016$

Jetz, W., \& Rahbek, C. (2002). Geographic range size and determinants of avian species richness. Science, 297(5586), 1548-1551. https://doi. org/10.1126/science.1072779

Karger, D. N., Conrad, O., Böhner, J., Kawohl, T., Kreft, H., Soria-Auza, R. W., ... Kessler, M. (2017). Climatologies at high resolution for the earth's land surface areas. Scientific Data, 4, 170122. https://doi. org/10.1038/sdata.2017.122

Keppel, G., Gillespie, T. W., Ormerod, P., \& Fricker, G. A. (2016). Habitat diversity predicts orchid diversity in the tropical south-west Pacific. Journal of Biogeography, 43(12), 2332-2342. https://doi.org/10.1111/ jbi.12805

Kier, G., Kreft, H., Lee, T. M., Jetz, W., Ibisch, P. L., Nowicki, C., ... Barthlott, W. (2009). A global assessment of endemism and species richness across island and mainland regions. Proceedings of the National Academy of Sciences USA, 106(23), 9322-9327. https://doi. org/10.1073/pnas.0810306106

Kissling, W. D., \& Carl, G. (2008). Spatial autocorrelation and the selection of simultaneous autoregressive models. Global Ecology and Biogeography, 17(1), 59-71.

Kissling, W. D., Eiserhardt, W. L., Baker, W. J., Borchsenius, F., Couvreur, T. L., Balslev, H., \& Svenning, J. C. (2012). Cenozoic imprints on the phylogenetic structure of palm species assemblages worldwide. Proceedings of the National Academy of Sciences USA, 109(19), 7379-7384.

Kreft, H., \& Jetz, W. (2007). Global patterns and determinants of vascular plant diversity. Proceedings of the National Academy of Sciences USA, 104(14), 5925-5930. https://doi.org/10.1073/pnas.0608361104

Kremer, A., Ronce, O., Robledo-Arnuncio, J. J., Guillaume, F., Bohrer, G., Nathan, R., ... Schueler, S. (2012). Long-distance gene flow and adaptation of forest trees to rapid climate change. Ecology Letters, 15(4), 378-392. https://doi.org/10.1111/j.1461-0248.2012.01746.x 
Lomolino, M. V., Brown, J. H., \& Sax, D. F. (2009). Island biogeography theory: Reticulations and re-integration of 'a biogeography of the species'. In J. B. Losos, \& R. E. Ricklefs (Eds.), The theory of island biogeography revisited (pp. 13-51). Princeton, NJ: Princeton University Press.

Losos, J. B., \& Schluter, D. (2000). Analysis of an evolutionary species-area relationship. Nature, 408(6814), 847-850. https://doi. org/10.1038/35048558

Ma, Z., Sandel, B., \& Svenning, J. C. (2016). Phylogenetic assemblage structure of North American trees is more strongly shaped by glacialinterglacial climate variability in gymnosperms than in angiosperms. Ecology and Evolution, 6(10), 3092-3106. https://doi.org/10.1002/ ece3.2100

McFadden, I. R., Sandel, B., Tsirogiannis, C., Morueta-Holme, N., Svenning, J.-C., Enquist, B. J., \& Kraft, N. J. B. (2019). Temperature shapes opposing latitudinal gradients of plant taxonomic and phylogenetic $\beta$ diversity. Ecology Letters, 22(7), 1126-1135. https://doi. org/10.1111/ele.13269

Mishler, B. D., Knerr, N., González-Orozco, C. E., Thornhill, A. H., Laffan, S. W., \& Miller, J. T. (2014). Phylogenetic measures of biodiversity and neo-and paleo-endemism in Australian Acacia. Nature Communications, 5, 4473. https://doi.org/10.1038/ncomms5473

Morrissey, M. B., \& Ruxton, G. D. (2018). Multiple regression is not multiple regressions: The meaning of multiple regression and the nonproblem of collinearity. Philosophy, Theory and Practice in Biology, 10(3), 1-24.

Myers, N., Mittermeier, R. A., Mittermeier, C. G., da Fonseca, G. A. B., \& Kent, J. (2000). Biodiversity hotspots for conservation priorities. Nature, 403(6772), 853-858.

Nathan, R. (2006). Long-distance dispersal of plants. Science, 313(5788), 786-788. https://doi.org/10.1126/science.1124975

Novotny, V., Drozd, P., Miller, S. E., Kulfan, M., Janda, M., Basset, Y., \& Weiblen, G. D. (2006). Why are there so many species of herbivorous insects in tropical rainforests? Science, 313(5790), 1115-1118. https ://doi.org/10.1126/science.1129237

Ohlemüller, R., Anderson, B. J., Araújo, M. B., Butchart, S. H., Kudrna, O., Ridgely, R. S., \& Thomas, C. D. (2008). The coincidence of climatic and species rarity: High risk to small-range species from climate change. Biology Letters, 4(5), 568-572. https://doi.org/10.1098/ rsbl.2008.0097

Olson, D. M., Dinerstein, E., Wikramanayake, E. D., Burgess, N. D., Powell, G. V. N., Underwood, E. C., ... Kassem, K. R. (2001). Terrestrial ecoregions of the world: A new map of life on Earth. BioScience, 51(11), 933-938. https://doi.org/10.1641/0006-3568(2001)051[0933:TEOTWA]2.0.CO;2

Orme, C. D. L., Davies, R. G., Olson, V. A., Thomas, G. H., Ding, T. S., Rasmussen, P. C., ... Blackburn, T. M. (2006). Global patterns of geographic range size in birds. PLoS biology, 4(7), e208.

Pebesma, E. J., \& Bivand, R. S. (2005). Classes and methods for spatial data in R. R news, 5(2). Retrieved from https://cran.r-project.org/doc/Rnews/

Pearse, W. D., Cadotte, M. W., Cavender-Bares, J., Ives, A. R., Tucker, C. M., Walker, S. C., \& Helmus, M. R. (2015). pez: Phylogenetics for the environmental sciences. Bioinformatics, 31(17), 2888-2890.

PRISM4 Paleoenvironmental Reconstruction. (2016). PRISM4 Biome land cover. Retrieved from http://geology.er.usgs.gov/egpsc/prism/ 4_data.html

Qian, H., \& Sandel, B. (2017). Phylogenetic relatedness of native and exotic plants along climate gradients in California, USA. Diversity and Distributions, 23(11), 1323-1333. https://doi.org/10.1111/ddi.12620

Queensland Government. (2014). Census of the Queensland flora 2014. Retrieved from https://data.qld.gov.au/dataset/census-of-thequeensland-flora-2014, checked on 2 May 2015.

Quintero, I., \& Jetz, W. (2018). Global elevational diversity and diversification of birds. Nature, 555(7695), 246-250. https://doi.org/10.1038/ nature 25794
R Core Team. (2017). R: A language and environment for statistical computing. Vienna, Austria: R Foundation for Statistical Computing. Retrieved from https://www.R-project.org/

Ray, N., \& Adams, J. M. (2001). GIS-based vegetation map of the world at the Last Glacial Maximum. Retrieved from https://www.ncdc.noaa. gov/paleo-search/study/6220

Rosauer, D. F., \& Jetz, W. (2015). Phylogenetic endemism in terrestrial mammals. Global Ecology and Biogeography, 24(2), 168-179.

Rosauer, D., Laffan, S. W., Crisp, M. D., Donnellan, S. C., \& Cook, L. G. (2009). Phylogenetic endemism: A new approach for identifying geographical concentrations of evolutionary history. Molecular Ecology, 18(19), 4061-4072. https://doi. org/10.1111/j.1365-294X.2009.04311.x

Royal Botanic Gardens and Domain Trust. (2017). PlantNET - The NSW plant information network system. Sydney, Australia: Author. Retrieved from http://plantnet.rbgsyd.nsw.gov.au, checked on 16 September 2016.

Sandel, B. (2018). Richness-dependence of phylogenetic diversity indices. Ecography, 41(5), 837-844. https://doi.org/10.1111/ecog.02967

Sandel, B., Arge, L., Dalsgaard, B., Davies, R. G., Gaston, K. J., Sutherland, W. J., \& Svenning, J. C. (2011). The influence of Late Quaternary climate-change velocity on species endemism. Science, 334, 660-664. https://doi.org/10.1126/science.1210173

Sandel, B., Monnet, A. C., Govaerts, R., \& Vorontsova, M. (2016). Late Quaternary climate stability and the origins and future of global grass endemism. Annals of Botany, 119(2), 279-288. https://doi. org/10.1093/aob/mcw178

Schluter, D., \& Pennell, M. W. (2017). Speciation gradients and the distribution of biodiversity. Nature, 546(7656), 48-55. https://doi. org/10.1038/nature22897

Short, P. S., Albrecht, D. E., Cowie, I. D., Lewis, D. L., \& Stuckey, B. M. (2011). Checklist of the vascular plants of the Northern Territory. Darwin, Australia: Department of Natural Resources, Environment, The Arts and Sport.

Smith, S. A., \& Brown, J. W. (2018). Constructing a broadly inclusive seed plant phylogeny. American Journal of Botany, 105(3), 302-314. https ://doi.org/10.1002/ajb2.1019

Smith, S. A., \& Donoghue, M. J. (2008). Rates of molecular evolution are linked to life history in flowering plants. Science, 322, 86-89. https:// doi.org/10.1126/science.1163197

Staab, M., Schuldt, A., Assmann, T., \& Klein, A. M. (2014). Tree diversity promotes predator but not omnivore ants in a subtropical Chinese forest. Ecological Entomology, 39(5), 637-647. https://doi. org/10.1111/een.12143

Stebbins, G. L. (1974). Flowering plants: Evolution above the species level. Cambridge, MA: Belknap Press.

Stein, A., Gerstner, K., \& Kreft, H. (2014). Environmental heterogeneity as a universal driver of species richness across taxa, biomes and spatial scales. Ecology Letters, 17(7), 866-880. https://doi.org/10.1111/ ele.12277

Stein, A., \& Kreft, H. (2015). Terminology and quantification of environmental heterogeneity in species-richness research. Biological Reviews, 90(3), 815-836. https://doi.org/10.1111/brv.12135

Svenning, J. C., Eiserhardt, W. L., Normand, S., Ordonez, A., \& Sandel, B. (2015). The influence of paleoclimate on present-day patterns in biodiversity and ecosystems. Annual Review of Ecology, Evolution, and Systematics, 46, 551-572. https://doi.org/10.1146/annurev-ecols ys-112414-054314

Svenning, J. C., \& Skov, F. (2004). Limited filling of the potential range in European tree species. Ecology Letters, 7(7), 565-573.

Takhtajan, A. (1986). Floristic regions of the world. Berkeley, CA: University of California Press.

Taylor, R. J., \& Regal, P. J. (1978). The peninsular effect on species diversity and the biogeography of Baja California. The American Naturalist, 112(985), 583-593. https://doi.org/10.1086/283299 
Tsirogiannis, C., \& Sandel, B. (2016). PhyloMeasures: A package for computing phylogenetic biodiversity measures and their statistical moments. Ecography, 39(7), 709-714. https://doi.org/10.1111/ ecog.01814

USDA; NRCS (2015). The PLANTS Database. Greensboro, NC: Edited by National Plant Data Team. Retrieved from http://plants.usda.gov, checked on 24 April 2015.

VicFlora (2016). Flora of Victoria. The State of Victoria, Department of Environment and Primary Industries. Retrieved from http://vicflora. rbg.vic.gov.au, checked on 30 November 2016.

Vie, J.-C., C. Hilton-Taylor, \& S. N. Stuart (Eds.) (2009). Wildlife in a changing world: An analysis of the 2008 IUCN Red List of Threatened Species. Gland, Switzerland: IUCN.

von Humboldt, A., \& Bonpland, A. (1807). Essai sur la géographie des plantes. Paris, France: Levrault, Schell and Co.

Weigelt, P., Jetz, W., \& Kreft, H. (2013). Bioclimatic and physical characterization of the world's islands. Proceedings of the National Academy of Sciences USA, 110, 15307-15312. https://doi.org/10.1073/ pnas.1306309110

Weigelt, P., König, C., \& Kreft, H. (2019). GIFT - A Global Inventory of Floras and Traits for macroecology and biogeography. Journal of Biogeography, 0, 1-28. https://doi.org/10.1111/jbi.13623

Weigelt, P., \& Kreft, H. (2013). Quantifying island isolation-insights from global patterns of insular plant species richness. Ecography, 36(4), 417-429. https://doi.org/10.1111/j.1600-0587.2012.07669.x

Western Australian Herbarium. (2017). FloraBase - the Western Australian Flora. Edited by Western Australian Herbarium. Department of Biodiversity, Conservation and Attractions. Retrieved from https:// florabase.dpaw.wa.gov.au/, checked on 16 September 2016

Williams, P., Gibbons, D., Margules, C., Rebelo, A., Humphries, C., \& Pressey, R. (1996). A comparison of richness hotspots, rarity hotspots and complementary areas for conserving diversity of British birds. Conservation Biology, 10(1), 155-174. https://doi.org/1 0.1046/j.1523-1739.1996.10010155.x
Willis, C. G., Franzone, B. F., Xi, Z., \& Davis, C. C. (2014). The establishment of Central American migratory corridors and the biogeographic origins of seasonally dry tropical forests in Mexico. Frontiers in Genetics, 5, 433. https://doi.org/10.3389/fgene.2014.00433

Zanne, A. E., Tank, D. C., Cornwell, W. K., Eastman, J. M., Smith, S. A., FitzJohn, R. G., ... Beaulieu, J. M. (2014). Three keys to the radiation of angiosperms into freezing environments. Nature, 506(7486), 89-92. https://doi.org/10.1038/nature12872

\section{BIOSKETCH}

We are a group of researchers interested in obtaining a global understanding of tree distributions and identifying hotspots of conservation priorities. We hope that this will provide useful input to global policies to support effective conservation efforts.

\section{SUPPORTING INFORMATION}

Additional supporting information may be found online in the Supporting Information section at the end of the article.

How to cite this article: Sandel B, Weigelt P, Kreft H, et al. Current climate, isolation and history drive global patterns of tree phylogenetic endemism. Global Ecol Biogeogr. 2020;29: 4-15. https://doi.org/10.1111/geb.13001 